MedieKultur | Journal of media and communication research | ISSN 1901-9726

Article

\title{
Making fictions sound real \\ - On film sound, perceptual realism and genre
}

\section{Birger Langkjær}

MedieKultur 2010, 48, 5-17

Published by SMID | Society of Media researchers In Denmark | www.smid.dk The online version of this text can be found open access at www.mediekultur.dk

This article examines the role that sound plays in making fictions perceptually real to film audiences, whether these fictions are realist or non-realist in content and narrative form. I will argue that some aspects of film sound practices and the kind of experiences they trigger are related to basic rules of human perception, whereas others are more properly explained in relation to how aesthetic devices, including sound, are used to characterise the fiction and thereby make it perceptually real to its audience. Finally, I will argue that not all genres can be defined by a simple taxonomy of sounds. Apart from an account of the kinds of sounds that typically appear in a specific genre, a genre analysis of sound may also benefit from a functionalist approach that focuses on how sounds can make both realist and non-realist aspects of genres sound real to audiences.

\section{Making things perceptually real}

Moving pictures have often been acknowledged for their realism. They produce life-like movements and have the capacity to move their audiences emotionally, two characteristics that were pivotal for the work of Hugo Münsterberg, André Bazin and Siegfried Kracauer (Münsterberg, 1916; Bazin, 1971; Kracauer, 1960), as well as being fundamental in more recent cognitive film theory (Messaris, 1994; Anderson, 1995; Grodal, 1997).

In the article "On the Impression of Reality in the Cinema", Christian Metz places special 
emphasis on the realness of movements in film: "Because movement is never material but is always visual, to reproduce its appearance is to duplicate its reality" (Metz, 1974, p. 9).

In general, the lifelike appearance of the moving images and the impression of reality they trigger can be coined "perceptual realism". This perceptual realism is different from realism in terms of content, as the basic lifelike qualities of persons, objects and movements are not related to whether persons, objects and movements occur in a realistic or a nonrealistic fictional world. As a general rule, films that can be described as portraying realism in terms of theme and content and films that embrace spectacular genres such as fantasy, adventure and science fiction all rely on perceptual realism. Even though a science fiction film may not be in accordance with our present knowledge about physical reality, it may realise its futuristic events with naturalistic detail and display persons, objects and events in ways that make immediate sense in terms of space, time and causality.

In an article on visual special effects called "True Lies", Stephen Prince specifies the notion of perceptual realism: "Perceptual realism designates a relationship between the image or film and the spectator, and it can encompass both unreal images and those which are referentially realistic. Because of this, unreal images may be referentially fictional but perceptually realistic" (Prince, 1996, p. 32).

From this perceptual point of view, all film genres are - or may be - equally real. Thus, the realism of the moving images does not stem from their absolute likeness to reality, just as their realism is not dependent on depicting an ordinary reality. It is rather that the moving images mime aspects of reality only to such an extent that they activate kinds of perceptual processes that would also be activated if the object considered was not a representational form but rather an unmediated visual experience: "For naturally generative systems of representation work by exploiting our visual capacities to recognise the object represented, and so the experience of recognising a picture of a horse is in an important respect like the experience of recognising a horse when you see one" (Currie, 1995, p. 90). On this level of automatic perception, the brain does not distinguish in terms of the ontology of the phenomenon, that is, whether the stimuli are caused by, respectively, real or represented phenomena (Anderson, 1995; Grodal, 1997).

But even though films activate a set of processes in the brain and the perceptual system that would also be activated in a non-mediated context, they also process other signals. For example, the natural and automatic feedback between visual and motor inputs are absent when we watch a movie, and, further, on a higher cognitive level our movie experience is governed by a different and more general kind of knowledge, such as the fact that we are in a movie theatre. This gives the movie experience its dual quality, its appearance - at one and the same time - as real and as artefact.

This notion of perceptual realism also implies that we have to be careful about how we conceive the issue of realism in relation to sound. On the one hand, sound in a movie contributes to the sense of presence and reality. In the words of film theoretician Béla Balázs, "it is the business of the sound film to reveal for us our acoustic environment" (Balázs, 1952/1970, 
p. 197). Siegfried Kracauer, who emphasised that the film medium was first and foremost a visual medium, notes that sounds have "the quality of bringing the material aspects of reality into focus" (Kracauer, 1960, p. 124). The quotes from these theorists suggest that sound is intimately linked to how the film reveals and makes real physical aspects of the fiction.

On the other hand, you only have to listen for a short time to a randomly selected feature film in order to discover that the sounds are not unmediated sounds from the world around you, but rather are sounds from a fiction. Similar to the moving images, the sounds have a dual quality, both amplifying the reality of the fiction and so obviously giving away the movie as an artefact. It has been argued by John Belton that developments in sound technology have not so much been used to enhance realism as to remove the movie experience from realism (Belton, 1985). In any case, most of the sounds in a feature film, apart from dialogue and music, are Foley sounds (or Geräusch) that for various reasons are considered to be better or more convincing than the original sound recording, just like the mix of sounds and their volume are regulated in ways that sound more like movies than reality (see Leeuwen, 1999, on the use of sound perspective in film and other media). Tomlinson Holman describes Foley-sounds as "hyper-real", that is, "sound recordings for film and television are often an exaggeration of reality" because the many sounds compete for our attention and therefore have "to be rather overemphatically stated, just to 'read' through the clutter" (Holman, 2002, p. xviii). But the hyper-real character of each sound is not necessarily experienced as such by the film audience: "heard in isolation, the recordings seem silly, overhyped, but heard in context, they assume a more natural balance" (Holmann, 2002, p. xviii).

\section{Spatial correlations versus continuity: Sound/image}

Another aspect of whether or not film sounds sound real is related to the question of sound space, especially concerning whether sound scales and image scales fit or not.

Rick Altman has described the norms for sound recording and mixing established in the early years of sound film as characterised by a non-match between visual and auditory space (Altman, 1992). His explanation for this is that any new media inherits its representational norms from previous media. Thus, the sound film inherited its practice from the radio in regard to two central aspects. First, during dialogue recording on the sound stage, the microphone was held close to the speaker in order to make intelligible close-up dialogue, and, secondly, the sound track, including any location sound, was not to be co-ordinated with the visual editing but was to be kept continuous. In the film media this implies that the audience does not hear the sounds of a scene from where it is seen. As the camera positions change during a scene, the sound does not follow this shift in visual perspective but continues. Especially the use of the boom mike has a great influence on the smooth dialogue recording: "The uniform sound track has become the rule, unmatched to and independent of the image" (Altman, 1992, p. 57). This practice prioritised intelligibility by avoiding variations in distance between speaker and microphone and by keeping the sound 
level continuous. "The construction of a uniform-level sound track, eschewing any attempt at matching sound scale to image scale, thus takes its place alongside the thirties' numerous invisible image-edition devices" [...].

Thus far, I believe that Altman gives a good, concise description of those early practices that became the norm also in later film practices (see also Lastra, 2000). But the joint kind of theoretical and historical explanation he gives seems more dubious to me. Later in his article, Altman sums up his argument:

[...] the varied-scale editing practices developed during the silent period move the spectator around at a dizzying pace. Far from inheriting a single place, the spectator must fight to integrate the multiple positions allotted by the film into a single unified home. While this wanderlust is partially cured by a learned, and thus historically ground, ability to insert shots of various scales into a coherent Gestalt of filmic space, it is only with the aid of a continuouslevel sound track that the spectator finds a comfortable home [...] this process serves to constitute more completely the spectator's unconscious self-identity as auditor, thus providing a satisfying and comfortable base from which the eyes can go flitting about, voyeuristically, satisfying our visual desires without compromising our unity and fixity. (Altman, 1992, p. 62)

Two things in this quote appear strange to me. First is the assumption that the spectator has to fight to integrate different visual shots during a scene because it somehow compromises the unity of the spectator and, in relation to this, that the uniform sound level somehow cures this potential fragmentation. Second, Altman's only explanation is historical. Thus, it is implied that the ability to make sense of different shots is not something that audiences in some sense or another are already capable of, but it is something that audiences have learned (from zero?) at some historical point.

I will neither argue that history does not play a role, nor that it makes no sense to see aesthetic practices, including sound, as conventional. But I do think we need to put greater emphasis on natural explanations, that is, seeing norms as something that does not come out of nowhere but as something that is often - at least partially - grounded in some natural explanation. Thus, the interaction between visual editing and sound continuity may also be related to more basic perceptual mechanisms than acknowledged by Altman. In the following, I will focus on some of those differences between vision and hearing.

Most of the visual field is peripheral. The fovea (the small part of the inner eye that provides the sharpest vision) covers less than 2 percent of our overall visual field. Therefore, the eye is in constant activity and changes its focus. Vision scans the world by small but quick movements of the eye. Yet we do not perceive the world as jumping around in jerky movements because we get different kinds of feedback. The jumping is a result of our own activity and is thus neutralized as part of our perception. Hearing, however, is not that selective. We can hear 360 degrees around and it is only to a small degree that the ear can turn up or down for the perceived sound volume. In any event, sounds do not disappear because I turn my head or turn my back to them. My turning around will change some of its 
characteristics but only so in a continuous stream. If a sound stops, it is either because what originally created the sound no longer makes a sound or because the sound is blocked: the car has stopped, a conversation has come to an end, or somebody in the noisy apartment next door just closed the door. Whereas changes in visual input are related both to the world and to the perceiver, changes in the aural input are first and foremost related to activities in the world (Branigan, 1997; Langkjær, 2000; Langkjær, 2006). This makes sound a central provider of information about physical changes in our environment. J. Anderson characterises hearing as "a radar" that detects changes and enables us to shift our attention toward something specific (Anderson, 1995).

On the level of perception, continuous sound is more true to every day perceptual experience than the model of recreating some pro-filmic situation by matching sound and image scales. A match between sound scale and image scale would entail a discontinuous sound and thereby indicate changes - not in the world of fiction but in the making of the fiction. A discontinuous sound would mark the film an artefact rather than highlighting the events in the fiction.

There are also other factors that downplay the need to match scales. For one thing, it is notoriously difficult to judge distance by sound. The perceived sound level not only depends on distance but also on the space the sound waves moves through on their way to the ear (Holman, 2000). In general, we are better equipped to assess sounds relatively than in absolute measurements, a fact of human perception and experience that also accounts for how we perceive differences in temperature, in light intensity etc. (Styles, 2005). Thus, we can probably perceive certain sounds as closer to us than others, but whether a truck is $\mathbf{2 0}$ or $\mathbf{4 0}$ metres away is much more difficult to assess. It is also a complicating fact that the experience of sound level depends on what other sounds can be heard. A dripping tap that was un-attended during the day can turn into a highly enervating sound at night. Thus, both the tolerance to variations in physical distance and the preference for continuity sound in most film practice is more consistent with natural perception than matching sound and image scale. The practice of rendering sound as an auditory stream in which changes in sound indicate changes in the fictional world, seems to "overrule" a model that synchronises visual and auditory markers of space and distance. But this is neither because of some historical and arbitrary norms nor because visual editing threatens the unity of the spectator. Rather, these film aesthetic practices adapt themselves - at least in the specific aspect addressed above - to basic rules of human perception.

\section{Synchronicity and perceptual tolerance: Can chalk drawings bark?}

In a frequently cited footnote in a frequently cited article (which actually is an excerpt from a book that is about something entirely different), Christian Metz writes that the film's images in many ways distorts normal visual perception, for example, through the use of different lenses, by using a rectangular frame etc.: "But auditory aspects, providing that the 
recording is well done, undergo no appreciable loss in relation to the corresponding sound in the real world: in principle, nothing distinguishes a gunshot heard in a movie from a gunshot heard on the street." (Metz, 1985, p. 161)

This is in many ways an odd statement, though it is completely consistent - indeed, virtually identical - with a host of other theorists (from Balázs to Cavell). Many know that the majority of sounds - apart from the dialogue - are made after the filming. Further, these sounds are most often not produced by the kind of activity that the pictures otherwise suggest. Just as the practice of NOT adjusting the distance between sound scale and image scale may seem strange at first, the use of Foley sounds may appear strange. Why is it that soundmen may use, let's say, the sound of two coconuts instead of a recording of real horses, or press their fingers against a plastic bag with salt or icing sugar to indicate steps in (different types of) snow? Despite tight budgets and time-schedules in post-production, it is likely that they could record a real horse or some real steps in the snow and do so on a real location.

This indicates that movies profit from a high degree of perceptual tolerance from their audiences in the sense that what can be counted as perceptually real is not necessarily what sounds like reality in and of itself. Perceptual realism in terms of sound is not a question of matching reality and representation, but rather a question of how the representation activates perceptual processes that in some important aspects are like the perception of unmediated reality. And, further, the reference to reality is a tricky one for several reasons. First, both physical and psycho-acoustical aspects of sounds are very dependent on the placement of the listener in a specific physical environment. This means that in natural audio perception, people have to recognise the "same" kind of sound under very different circumstances. Secondly, in some cases our knowledge about what a real sound sounds like depends on sources other than real-life interaction, like gun shots in crime films, space ships in science fiction or exotic animals in nature programmes on television shot in places we have never been ourselves. This makes claims on reality a very complex matter.

But it still needs to be explained how "hyper-real" sounds, as Holmann coins them, can not only be accepted but also perceived as something that lends credence to the fiction. I will try to make this more intelligible by posing two questions and giving two partial explanations. These cannot fully explain the phenomenon, but they can nevertheless give some indications. The questions are:

1) Why is it that fake sounds can be accepted as part of the fiction?

2) Why (or in what sense) do fake sounds get experienced as more real than real sounds?

While the first explanation is primarily linked to automatic perceptual processes, the second explanation will be a mix of several factors.

It seems beyond doubt that synchronicity between a visual and an auditory pattern automatically triggers the experience that the sound is the sound of what we see. This is yet another quote from Anderson: "Temporal synchrony is a basic mechanism for linking 
sound and image. The processing 'rule' may be this: If the auditory and visual events occur at the same time, the sound and image are perceived as one event" (Anderson, 1995, p. 83). Anderson conceives this as part of a larger perceptual system which perceives "amodal invariants". If stimuli in different sensory modalities share some features, such as rhythmic patterns, then we perceive them as part of the same phenomenon in the world. Another way to put this is that although various sensory inputs come to us in different sensory modalities, we perceive them as part of the world.

Turning to actual film practices, there are of course cases that challenge this. When Lars von Trier makes static chalk drawings bark, as in Dogville (2003), it is hard to experience this as something that really happens in the fiction. This is partly because chalk drawings do not bark and partly because even though the drawing of a dog and the sound of a dog are conceptually related, they do not share any amodal invariants to lend them any perceptual naturalness, such as would have an animated drawing synchronised to a sound. Actually, contemporary animation films have no problem giving us the experience that sound is linked to events in the fiction as long as they create "amodal invariants" by synchronising visual movement and auditory event. Further, Michel Chion puts great emphasis on synchronicity: "For the spectator, it is not acoustical realism so much as synchrony above all [...] that will lead him or her to connect a sound with an event or detail" (Chion, 1994, pp. 22-23).

In general, the perceptual system is very tolerant to sounds as long as they are synchronous with or do not contradict visual traits. This also applies to speech perception as demonstrated by an experiment by McGurk and MacDonald (1976). In this experiment, subjects were exposed to a movie in which the pictures showed people saying ga-ga-ga, while the soundtrack said ba-ba-ba. The subjects did not choose one over the other but integrated the two inconsistent stimuli by producing a compromise based on the similarity between the two. Thus, the majority of the subjects neither perceived ga nor ba, but rather da-da-da.

This does not explain why sound men replace the real sounds with sound effects, but the experiment indicates one type of explanation (which far from exhausts the subject) as to why it can be done. Human perception works to make us navigate in a coherent world, both physical and social in nature. Perception assumes coherence to such an extent that if there is none available, it creates the most likely. Thus, the built-in mechanisms for perception create useful illusions. These can be used by the film to make a fictional world appear as real. Conversely, these mechanisms can of course also be played upon by going against them. Like when chalk drawings bark.

\section{Partial similarity as characterisation}

But why is it that fake sounds can sound more real than real sounds? First, not just anything can replace location sounds. A Foley sound must at least have a partial likeness to 
the kind of sound for which it is a substitute. This applies first and foremost to how the sound unfolds in time but also to its timbre and frequency register. Conversely, there will often be characteristics of a natural sound which are amplified by the use of fake sounds. A gunshot may sound very heavy (low frequencies), steps on the floor may sound loud and distinct, and a bundle of keys may rattle with a delicate, treble-filled and metallic ringing sound. These sounds certainly do not sound like a documentary recording of, respectively, a gun shot, some steps and a bunch of keys. It is rather that those sounds characterise these objects and events in certain ways. The heavy gun shot becomes more powerful, the loud and distinct steps sound more determined and the tiny metallic ringing sound gives the keys a magic touch. A Foley sound takes part in both creating and characterising an event.

This is related to what Michel Chion calls "added value": "By added value I mean the expressive and informative value with which a sound enriches a given image so as to create the definite impression, in the immediate or remembered experience one has of it, that this information or expression 'naturally' comes from what is seen, and is already contained in the image itself." (Chion, 1994, p. 5)

This idea of "added value" includes sound effects, music and voiceovers. One may object that these three kinds of audio elements make sense in very different ways. For one thing, both language and music seem to be much more complex structures than a single sound effect. Further, "added value" tends to name the effect rather than the components of the process. With the concept of "characterisation", I intend to stress the specific informationvalue that sound effects give away to the film audience by focusing on what it is in each sound (its audio features) that characterises an event in the fiction in a certain way.

Thus, sound in the fiction film is neither there to provide evidence of the original recording situation (Altman), nor to be reduced to a substantial category of things, as it is otherwise indicated by Metz when he writes that we only understand a given sound when we know its source: "name the source of the sound rather than the sound itself" (Metz, 1985, p. 155). It is clear that sounds become meaningful by the fact that we recognise them as sounds of certain activities. But the movie experience implies something more than the listing of sounds and their causes. First, film sound is very much about structuring and timing attention. Secondly, sounds not only identify an event, they also characterise events so they make sense in a certain way. The sounds of steps are not just the sound of steps, but also the sound of some specific steps: there are determined or hesitating steps, loud or soft, fast or slow. By doing this, the sound enhances the fictional reality and gives it a particular toning, which is a prerequisite for realising a film's intentions.

\section{Perceptual realism and the question of genre: Two kinds of approaches}

One question concerns whether or to what extent those traits I have mentioned in relation to sound and perceptual realism are related to movie genres. Do the realism of techniques such as continuity sound - a kind of audio equivalent to visual continuity-edition practices 
- and sounds which in and of themselves may appear non-naturalistic also relate to the question of genre? I have previously stressed that on the level of perception, all genres may be equally real. The basic argument is that even though our known world does not include huge monsters that speak backwards and have seven legs, a film may nevertheless realise this fiction in a way that is perceptually persuasive thus giving a sense of credence to it. We actually hear and see these monsters like they would appear if they existed, that is, visual special effects and Foley sounds make them appear perceptually real to us. As long as the visuals make movements appear smooth or display coherent visual depth cues and the Foley sounds characterise events in meaningful ways, we tend to accept them as credible information about true events in the fiction.

But fictions are different in kind, especially when it comes to genre. Is it the case that our tolerance to sound is related to the generic context in which it occurs? Do cars sound louder in action movies than in melodramas? Does it sound different when people fall (by accident) in a comedy than in a psychological drama? Can you hear the film genre via its soundtrack?

The answers to these questions can be sought in at least two ways. First, it is obvious that certain genres give priority to certain types of events. There are probably more explosions in action movies and more pump gun-shootings in gangster movies than is the case in most other film genres. The nature of the sounds and the actions they make salient tend to indicate a genetic affinity. In this way, a set of typical sounds may be part of a genre-catalogue in the same way as elements of content and mise-en-scene. But does this count for all genres? What about sound in melodrama? You may hear it is a melodrama through dialogue and music, but can a melodrama be recognised as such by its sound effects? Further, some crime films do not necessarily involve noisy weapons and the comedy in romantic comedies rely more often on stylisation of character and situation, e.g., creating embarrassing moments, than on those kinds of stylised sounds used in animation and in farces. In these cases, sound does not seem to give away the film genre.

When genre films can be recognised as such by their use of certain sounds and when they can not, another and complementary approach may be considered. Rather than counting specific kinds of sounds in specific kinds of films, it might also be rewarding to ask whether some sound parameters and norms change in relation to genres. What kinds of genres play with or refuse to make use of continuous soundtracks? (And what kinds of effects do they achieve by doing that?) What kinds of genres break with the principle of synchrony? (And what kinds of effects do they achieve by doing that?) Do generic forms make a difference to the kind of stylisation and characterisation that can be tolerated in relation to sound?

So, another way to address the relationship between sound and genre (rather than as a simple sound taxonomy) is to focus on what kinds of tasks the sounds will have to perform in relation to specific genres. It is quite clear that there are a great many functions of sound that will apply across genres. Thus, sound can create a sense of a specific environment (for example, are we in the countryside or in a city?), it can focus our attention by emphasising 
specific events or it can focalise on characters' mental states by use of subjective sound effects (see also Langkjær, 1996, pp. 157-158). In such instances, neither a taxonomy nor a functional approach to sound will make sense as something specifically related to a genre. But in certain genres, the films have to evoke certain types of fictional events and specific kinds of spectator experiences. Here, sound may play a central role. This also counts for films which on the level of content and action exceed contemporary realism, as is the case, among other genres, in science fiction and adventure films. In such films, what may seem strange is to some extent naturalised. Thus, the film will try to make its audience accept space ships, amorphous bodies, and unrealistic human movements as a real part of the fiction in films, such as, respectively, in Star Wars (1977), Terminator 2 (1991) and The Matrix (1999). The sounds make the audience experience non-realistic events as plausible, since the sounds add an immediate and perceived reality to the movements on the screen.

\section{Making the unreal real: Some examples}

I will give a few examples from different types of science fiction films and otherwise adventurous films of how the sound characterises characters and events in ways that give the fiction a quality of perceptual (rather than ontological) reality.

In a very basic sense, film sound often provides a physical characterisation of the key elements of a scene (Kracauer, 1960; Chion, 1994; Langkjær, 2000). Thus, the digitally made dinosaurs in Jurassic Park (1993) are given a frightening and credible physicality by sustained and low frequency sounds of their footsteps. But sound can also focalise our perception by giving us the impression of experiencing the events from a specific location. This is essential in Being John Malkovich (1999), where the audience will have to accept that the characters can pass through a small door that, ultimately, makes them enter the mind of John Malkovich. The first time it happens for the film's male protagonist, the situation is created through a combination of a maintained point-of-view shot (within a visible framing) and sounds consisting of a weak midrange area as if we heard things through a filter. This marks the difference between seeing as John Malkovich would see and really being John Malkovich, that is, it allows us at once to look at what the protagonist and John Malkovich are looking at while the visual framing and the manipulated sound mark the difference between the two. This filtering of sound is only heard the first time our protagonist enters John Malkovich's head, a scene in which it is important for the film to make its audience accept the premise. In the following scenes, once the audience is assumed to have accepted this, the sound is without this mediated quality. Thus, the sound is to give an immediate experience of the special dual perceptual position, which is one of the film's non-realistic premises.

A film such as The Matrix relies on moving between spaces perceived as physical reality and spaces perceived as virtual. When Morpheus explains to our hero about the Matrix, it is not just the room that appears white and empty, thereby enhancing the unreal quality of the scene. Also the background sounds disappear. But at other times, the events in the 
matrix are supposed to be experienced as physical, especially when they have deadly consequences outside the matrix. This also applies to events that otherwise violate general physical principles. This happens in a duel on a roof between the hero and one of the agents, in which it appears that the hero for the first time is able to move in ways that transgress the general rules of the matrix system. The abnormal speed of the hero's movements is displayed by slow motion as he moves backwards and thereby avoids the projectile the agent has fired at him at a rather close distance. The slow motion not only makes the audience notice details of the action, but this extended timescale (a change in time/movement ratio) also makes his un-realistic reaction seem possible, because the slow motion makes the hero react to things as if perception and reaction are much faster than normal.

But how does the film emphasise this aspect of the action in terms of sound? Whereas visual slow motion does change the movement, but does not change our ability to recognise persons and objects, slow motion sound will either deform the sound object to such an extent that it will be difficult or even impossible to recognise by lowering the frequency register (the analogue model) or extending the sound in time (the digital model). In The Matrix, a third option is used, as the fastness of the hero is revealed by extending the sound movement in space and increasing its "size", as if the projectile was a missile and had to run a much longer course to hit its target. It sounds more like a missile doing a long ballistic curve through a large space than a simple close-range gunshot. Thus the sound space is changed as to extend the projectile's trajectory and thereby to provide an immediate experience that there is more time before the bullet hits than is the case in a normal Newtonian world. In that sense, the sound enhances our immediate understanding of that kind of time-dimension which is real in the fiction. Whereas the pictures manipulate time by slowing down visual movements, the sound manipulates time by extending the audio space.

Other films break with the general rule about sound continuity during actions and events and across visual cuts. In Le fabuleux destin d'Amélie Poulain (2001), visual montage is often combined with blunt sound-cuts, thereby making the cutting an event in and of itself. This way of paying attention to style rather than fictional events enhances the sense of the movie being narrated, and thereby it fits well with the often unbelievable ways that the voice-over narrator connects the adventurous events. In this case, breaking the rules of perceptual realism makes perfect sense in relation to its genre and overall narrative form.

These few examples do not imply that certain genres sound in certain ways. Even though some genres do indicate a preference for certain sounds, for all genres, specific aspects of the action should be perceived on an immediate level and as a natural part of the fiction, even when it comes to representations of non-realistic events. In all cases, the sound is not just the sound of something by which we identify the characters and objects as characters and objects of a certain kind (Metz, 1985). Rather, sound characterises, creates and brings life to a number of actions and events. 
Article: Making fictions sound real - On film sound, perceptual realism and genre

\section{Coda}

In this article, I have argued along two lines. First, some sound techniques, which on a first account may appear artificial, can nevertheless in the overall audiovisual context lend credence to the kind of fictional events involved. Sound continuity does not correspond to or reproduce any "profilmic" recording space, but it does correspond to ways that we normally experience our environment through our ears. Further, sound effects that may sound artificial on a close hearing can nevertheless support our constant search for information and enhance our perception of actions, events and their implications in the fiction by characterising them in meaningful ways. Thus, continuity sound and sound effects as characterising devices may be considered features of mainstream film practice. This is how sound normally sounds and what it normally does.

Second, defining film genres in terms of sound may seem a less easy task than defining it by the pictures. Some genres such as war films, science fiction and crime films may also appear evidently so from the soundtrack alone. Others may less obviously belong to specific genres based on their sound effects alone. But this does not imply that sound is of lesser importance to these genres. The approach suggested in this article looks at genre-specific key moments in the films. Thus, it is a functionalistic approach. It indicates a method of analysis that focuses on genetic aspects of sound, both within a functional framework and in relation to basic perceptual conditions. Some films attract audience attention to their unusual narrative forms by a discontinuous soundtrack, whereas others enhance some characteristics of their sound effects in order to make a non-naturalistic event in a supernatural fiction credible. In this sense, genres may push the limits of what can be conceived of as perceptually real, also in terms of sound.

\section{References}

Altman, R. (1992). Sound space. In R. Altman (Ed.), Sound theory, sound practice (pp. 46-64). New York: Routledge/AFI.

Anderson, J. (1995). The reality of illusion. Carbondale: Southern Illinois University Press.

Balázs, B. (1970). Theory of the film. New York: Dover Publications, Inc. (Original work published 1952).

Bazin, A. (1971). What is cinema? Vol. II. Berkeley: University of California Press.

Belton, J. (1985). Technology and aesthetics of film sound. In E. Weiss \& J. Belton (Eds.), Film sound: Theory and practice (pp. 63-72). New York: Columbia University Press.

Branigan, E. (1997). Sound, epistemology, film. In R. Allen \& M. Smith (Eds.), Film theory and philosophy (pp. 95-125). Oxford: Oxford University Press.

Chion, M. (1994). Audio-vision. New York: Columbia University Press.

Currie, G. (1995). Image and mind. Cambridge: University of Cambridge Press.

Grodal, T. (1997). Moving pictures. Oxford: Oxford University Press.

Holman, T. (2002). Sound for film and television. Boston: Focal Press.

Kracauer, S. (1960). Theory of film. Princeton: Princeton University Press.

Langkjær, B. (1996). Filmlyd \& filmmusik. Copenhagen: Museum Tusculanum Press. 
Article: Making fictions sound real - On film sound, perceptual realism and genre

Langkjær, B. (2000). Den lyttende tilskuer. Copenhagen: Museum Tusculanum Press.

Langkjær, B. (2006). Mediernes lyd. En multimodal analysemetode. MedieKultur, 40, 14-26.

Lastra, J. (2000). Sound technology and the American cinema. New York: Columbia University Press.

Leeuwen, T. (1999). Speech, music, sound. Basingstoke: Macmillan Press. Ltd.

McGurk, H., \& MacDonald, J. (1976). Hearing lips and seeing voices. Nature, 264, 746-748.

Messaris, P. (1994). Visual literacy. Boulder: Westview Press.

Metz, C. (1974). On the impression of reality in the cinema. In Film Language (pp. 3-15). Oxford: Oxford University Press.

Metz, C. (1985). Aural objects. In E. Weiss \& J. Belton (Eds.), Film sound: Theory and practice (pp. 154-161). New York: Columbia University Press.

Münsterberg, H. (1916). The Photoplay. Appleton.

Styles, E.A. (2005). Attention, perception and memory: An integrated introduction. New York: Psychology Press.

Birger Langkjar

Associate Professor, Ph.D.

Department of Media, Cognition and Communication

University of Copenhagen, Denmark

bilang@hum.ku.dk 